\title{
Atypical bacterial pneumonia in the HIV-infected population
}

\author{
Breanne M. Head', Adriana Trajtman', Zulma V. Rueda², Lázaro Vélez ${ }^{3}$ and Yoav Keynan ${ }^{4,5,1^{*}}$
}

\begin{abstract}
Human immunodeficiency virus (HIV)-infected individuals are more susceptible to respiratory tract infections by other infectious agents (viruses, bacteria, parasites, and fungi) as their disease progresses to acquired immunodeficiency syndrome. Despite effective antiretroviral therapy, bacterial pneumonia (the most frequently occurring HIV-associated pulmonary illness) remains a common cause of morbidity and mortality in the HIV-infected population. Over the last few decades, studies have looked at the role of atypical bacterial pneumonia (i.e. pneumonia that causes an atypical clinical presentation or responds differently to typical therapeutics) in association with HIV infection. Due to the lack of available diagnostic strategies, the lack of consideration, and the declining immunity of the patient, HIV co-infections with atypical bacteria are currently believed to be underreported. Thus, following an extensive database search, this review aimed to highlight the current knowledge and gaps regarding atypical bacterial pneumonia in HIV. The authors discuss the prevalence of Chlamydophila pneumoniae, Mycoplasma pneumoniae, Coxiella burnetii, Legionella species and others in the HIV-infected population as well as their clinical presentation, methods of detection, and treatment. Further studies looking at the role of these microbes in association with HIV are required. Increased knowledge of these atypical bacteria will lead to a more rapid diagnosis of these infections, resulting in an improved quality of life for the HIV-infected population.
\end{abstract}

Keywords: Atypical, Bacteria, Pneumonia, HIV, Legionella, Chlamydophila, Mycoplasma, Coxiella, Tropheryma

\section{Background}

Bacterial pneumonia, the most frequent human immunodeficiency virus (HIV)-associated pulmonary illness, is a common cause of co-morbidity and mortality in the HIV population. Prior to the introduction of combination antiretroviral therapy (cART), bacterial pneumonia infection rates ranged from $3.9-20$ cases per 100 person-years in HIV-positive individuals and were predominantly due to opportunistic pathogens such as Streptococcus pneumoniae, Haemophilus influenzae, Staphylococcus aureus, as well as acute Mycobacterium tuberculosis infections [1-8]. Although bacterial pneumonia rates have decreased since the introduction of cART, rates remain 10 times higher among HIV-infected individuals than in healthy individuals $[2,4,5,9,10]$. Additionally, HIV-associated pneumonia remains the most common cause of hospital

\footnotetext{
* Correspondence: Yoav.Keynan@umanitoba.ca

${ }^{4}$ Department of Internal Medicine, University of Manitoba, Winnipeg, Canada

${ }^{5}$ Department of Community Health Sciences, University of Manitoba,

Winnipeg, Canada

Full list of author information is available at the end of the article
}

admission with up to 90 cases per 1000 persons occurring yearly $[5,11-13]$.

Currently, the diagnosis of pneumonia is based on clinical features and X-ray. The etiological diagnosis, however, is based on empirical data, culture, serology, nucleic acid amplification techniques (NAAT), and bronchoscopy [5, 14]. When choosing any of these diagnostics, a number of points must be considered. Although very informative, empirical data (i.e. patient history, recent travel, intravenous [IV] drug exposure, prior infections, or antibiotic exposure) can only aid in narrowing the scope of infection and is not definitive [5]. In contrast, culture allows bacterial identification and is considered the preferred method in diagnostics. However, incubation periods can be lengthy (depending on the growth rate of the microorganism), not all microbes are cultivable, and the sensitivity of the assay decreases if the patient has had any pre-treatment with antibiotics [15]. Serological tests rely on the patient's ability to mount an effective antibody response; however, in the case of HIV, this response is greatly reduced. 
Therefore, depending on the stage of HIV infection, serology may not be clinically useful [16]. Due to the low sensitivities of serology, NAAT (such as polymerase chain reaction $[\mathrm{PCR}]$ ) is becoming the diagnostic tool of choice for rapid identification of atypical bacteria in respiratory samples of HIV-infected and uninfected individuals $[14,17,18]$. However, although NAAT is highly specific, sensitivity has been shown to vary depending on the patient sample being tested (e.g. nasopharyngeal sample vs. induced sputum) [19, 20]. Moreover, although the presence of NAAT is becoming more prominent in developed nations, it is still not readily available in developing countries. In the event that a definitive diagnosis cannot be reached, more invasive techniques (e.g. bronchoscopy) may be used for sample collection (bronchoalveolar lavage [BAL] or biopsy). Although very beneficial, bronchoscopy is currently underutilized in respect to HIV and advanced immunosuppression, despite it being recommended for patients with low CD4 cell counts $(<200$ cells $/ \mu l)$. This underutilization is perhaps due to the fact that patients are too sick to undergo the BAL procedure, or due to the high volume of immunosuppressed patients admitted to hospital [5, 12, 21]. In addition, it can lead to complications such as bleeding and pneumothorax [5, 21].

Despite technological advancements, the etiology of HIV-associated pneumonia is identified less than $60 \%$ of the time, thus research looking into atypical pneumoniacausing agents is required $[5,9]$. Limited information is available regarding atypical bacterial pneumonia (i.e. pneumonia that does not respond to beta-lactams, one of the antibiotics typically prescribed to pneumonia patients with co-morbidities), with even less information about these infections in HIV [22]. Due to the lack of consideration, the role that atypical bacteria play in disease severity and patient outcome in HIV-associated pneumonia is unknown. Consequently, this review will highlight the bacteria-namely Chlamydophila pneumoniae, Mycoplasma pneumoniae, Coxiella burnetii, Legionella species and others-that is responsible for causing atypical bacterial pneumonia in HIV. Specifically, the review explores the current knowledge regarding the prevalence of these microbes in the HIV-infected population, as well as their clinical presentation, methods of detection, and treatment.

\section{Chlamydophila pneumoniae}

Chlamydophila pneumoniae, an obligate intracellular pathogen that has caused pulmonary infections all over the world, remains a particular problem in the HIVinfected population [23-26]. Studies by Trinh et al. [27] have demonstrated that $C$. pneumoniae pneumonia rates are as high as $60 \%$ in cART-treated HIV-infected children. Likewise, in the adult population, coinfections with HIV have been reported to range from 3 to $39 \%$ [28-31]. In general, HIV-associated C. pneumoniae pneumonia rates have been shown to be inversely proportional to the patient's CD4 cell count, occurring at 6.8, 15.7, and 25.2\% when CD4 counts are above 500, between 200 and 500, and below 200 cells/ $\mu$ l, respectively [30]. In other words, the rates increase with decreasing $\mathrm{CD} 4$, up to a quarter among individuals with advanced HIV and CD4 $<200$. In a retrospective analysis [29] of 319 adult pneumonia-infected HIV seropositive individuals, C. pneumoniae was cited as a co-pathogen with other microorganisms in approximately $2.2 \%$ $(n=7)$ of cases.

Much of the research on HIV-associated C. pneumoniae pneumonia arises from the post-cART era with little information on the effect of this microorganism in untreated HIV. However, of those that have been reported, it was found that the risk of acquiring C. pneumoniae pneumonia was 5 times higher in untreated HIV than in the general population [30,32, 33]. Regardless of these higher rates, the clinical course of disease is similar among both populations. Disease manifests as an acute respiratory infection (with focal pneumonia, pleural effusion, or bronchitis), although, as the degree of immunosuppression increases, more severe and diffuse interstitial pulmonary involvement and death can occur [29, 32, 34, 35]. Likewise, C. pneumonia infection has also been shown to cause chronic infections (e.g. arteriosclerosis or cardiovascular disease) [36].

Diagnosis of HIV-associated C. pneumoniae pneumonia is reliant on serology and NAAT. Microimmunofluorescence (MIF), a technique that indirectly measures the C. pneumoniae-specific antibody response, requires either single or convalescent serum samples to differentiate between a recent/current infection and a previous one $[27,30,29,34]$. However, severely immunosuppressed HIV-infected adults (with CD4 counts <200 cells $/ \mu \mathrm{L}$ ) have been reported to be unable to mount an effective IgG response [25]. Conversely, HIV patients may have an asymptomatic C. pneumoniae infection while co-infected with another pneumonia-causing pathogen, which poses another limitation on the utility of this diagnostic test [25, 29]. Consequently, NAAT tests on respiratory specimens (BAL or nasophayngeal swab) are recommended as they have shown promise for C. pneumonia diagnosis in HIV $[18,27,37]$. In fact, the United States Food and Drug Administration has approved a BioFire FilmArray NAAT for the detection of both C. pneumoniae and M. pneumoniae [37].

\section{Mycoplasma pneumoniae}

Mycoplasma pneumoniae, the most common Mycoplasma respiratory pathogen, accounts for approximately $20 \%$ of all pneumonias in the United States (US) general 
population, and 11.3-21.0\% (depending on the method of diagnosis) of all pneumonias in the US HIV-infected population, with higher rates correlated with the degree of immunosuppression [31, 38-40]. Indeed, in a study by Nadagir et al. [41], 18 of the 29 (62\%) HIV-positive, $M$. pneumoniae-infected children had a CD4 cell count of $<20$ cells/ $\mu \mathrm{L}$. Additionally, a depleted CD4 associated with advanced HIV disease has been shown to enhance $M$. pneumoniae establishment in the lungs [40-43]. However, similarly to C. pneumoniae, the majority of the data on HIV-associated $M$. pneumoniae lung infections is from treated HIV patients, with minimal information on its effect in untreated HIV.

Clinical manifestations of M. pneumoniae pneumonia in HIV are similar to those seen in healthy individuals. Cough (reported in 100\% of cases), anemia, arthralgia, dyspnea, and sore throat along with fever, rales, interstitial infiltrates, and lobar pneumonia are most commonly reported, making diagnosis nearly impossible based solely on clinical presentation [40-42, 38].

M. pneumoniae diagnosis relies on culture, serology, and NAAT [42, 44]. However, isolation requires up to 3 weeks incubation, limiting the practicality of this method in a clinical setting [40, 41, 38, 45]. Similarly, time is also a limiting factor for serology, as it is dependent on a convalescent serum sample [19]. Moreover, M. pneumoniae has been shown to persist within the host, with persistent IgM detectable years after infection $[38,41,42,45-50]$. Furthermore, due to the fact that up to $20 \%$ of healthy individuals do not develop $M$. pneumoniae-specific IgM combined with the impaired immune response associated with HIV infection, immunosuppressed HIV-infected patients may never develop a detectable antibody response altogether, which means this technique is not reliable for diagnosis in this population [38, 51]. In fact, Shankar et al. [40] found that culture was more reliable for diagnosing $M$. pneumoniae infections in HIV-positive individuals since it was able to identify infections in $31 \%(n=31)$ of their adult HIV population, while IgM enzyme-linked immunosorbent assay only identified $21 \%(n=21)$, highlighting that relying solely on serology could lead to a false negative. Consequently, multiple laboratories have developed NAAT methods (e.g. the BioFire FilmArray NAAT, or real-time PCR) for the detection of $M$. pneumoniae, although the Center for Disease Control and Prevention has indicated that few of these developed methods are actually acceptable for diagnostic assessment [37, 44, 52]. Nonetheless, these amplification techniques have demonstrated higher sensitivities and specificities compared to other diagnostics and have emerged as the new standard for $M$. pneumoniae pneumonia detection in HIV [44].

\section{Coxiella burnetii}

Coxiella burnetii ( $\mathrm{Q}$ fever) is an obligate intracellular bacterium capable of causing acute and chronic illnesses in both immunocompromised and immunocompetent individuals alike [53]. However, reports of HIVassociated Q fever pneumonia are currently limited. Of those that have been reported, majority of them are from the pre-cART era $[25,30,53,54]$. Nevertheless, information from the pre-cART era allows us to make inferences as to how C. burnetii will affect untreated HIV-infected patients, and those that have previously been treated with cART but have already progressed to AIDS.

In the $1990 \mathrm{~s}, \mathrm{Q}$ fever pneumonia rates were $0.3 \%$ in the general population and $9.7 \%$ in the untreated HIVseropositive adult population. During this time, HIVinfected individuals were reported to be 13 times more likely to contract Q fever than healthy individuals [54].

Like the other atypical pneumonias, the clinical course of C. burnetii pneumonia is similar in both HIV-positive and negative individuals [53]. Symptoms can last up to 10 days and are often non-specific (e.g. fever, headache, non-productive cough, myalgia); however, in $90 \%$ of cases involving HIV, lung nodules have been shown to occur.

Diagnosing HIV-associated Q fever pneumonia can be quite challenging due to the many clinical forms of the disease (e.g. acute or chronic pulmonary infection) and to the decreasing immunity associated with HIV [54]. Diagnosis is based on serology and NAAT, however the potential of false negatives seen in serology increases with HIV disease advancement [25, 30, 54]. Moreover, in $\mathrm{Q}$ fever endemic areas, single serum samples may result in false positives, thus convalescent serum samples may be required. NAAT, and, more specifically, PCR - a more promising alternative with high specificity-are not widely available $[55,56]$. Due to the lack of knowledge regarding when to test for HIV-associated Q fever pneumonia, C. burnetii diagnostics in HIV-infected patients are infrequently attempted and are likely to be underrepresented [30, 54, 57].

\section{Legionella pneumophila}

The opportunistic intracellular pathogen Legionella pneumophila is a particular problem in immunosuppressed patients, and is estimated to be responsible for $20 \%$ of all adult HIV-associated pneumonias (compared to $15 \%$ in the general population), although surprisingly very few cases have actually been reported to date [15, 58-64]. Of the cases that have been recorded, many have shown that HIV-infected patients (particularly those with advanced immunosuppression) often present with a more severe clinical presentation compared to normal individuals $[4,58,65]$. 
In general, L. pneumophila pneumonia symptoms are non-specific with significantly higher rates of cough, dyspnea, bilateral pulmonary involvement, and hyponatremia in people with $\operatorname{HIV}[58,62,66,67]$. However, atypical manifestations involving the gastrointestinal tract or the central nervous system may also occur, making initial diagnosis quite challenging [62, 66, 67]. Recurrent lung cavitation has been shown to occur almost exclusively in immunosuppressed patients and often occurs shortly after initiation of therapy $[58,60,68]$. Complications due to respiratory failure and higher mortality rates have also been seen [67].

L. pneumophila infections may be underrepresented in the HIV population due to the fact that routine screening for Legionella is not usually performed and requires a special request from the clinician [4, 63]. Diagnosing HIV-associated L. pneumophila pneumonia has traditionally been reliant on culture and the urinary antigen test $[62,69]$; however, culture requires specialized media, several days for growth, and still only has about $80 \%$ sensitivity [70]. For serology, depending on the severity of the patient's immunosuppression, measurable L. pneumophila antigen may not be detectable initially, resulting in a false negative for the urinary antigen test $[62,66]$. In a case by Franzin et al. [62], a negative urinary antigen result postponed L. pneumophila diagnosis in a cARTadhering, HIV-infected adult male until cultures were obtained (several days later). Thus, definitive diagnosis of HIV-associated L. pneumophila pneumonia has been reliant on two methods, both known to have their own respective limitations [62, 69]. Consequently, NAAT has become the new standard in diagnostics. Realtime PCR methods, targeting the Legionella mip gene, are considered to be more specific, sensitive and rapid compared to traditional diagnostics (with approximately a $15 \%$ increased yield over culture) and have been adapted for use in multiple laboratories; however, in developing nations, these automated techniques are not readily available $[17,71,72]$. Lastly, HIV patients are often co-infected with more than one pathogen which could mask infection with L. pneumophila. Consequently, L. pneumophila may play a much larger role in HIV-associated pneumonia than is currently anticipated.

\section{Non-pneumophila Legionellas}

Pneumonia by other non-pneumophila Legionella species accounts for $10 \%$ of all legionellosis in the general population (with Legionella micdadei and Legionella bozemanae accounting for $90 \%$ of these cases) with limited information regarding these infections in HIV. However, of the information that has been gathered, it seems that cART-adhering HIV-infected individuals have higher rates of nonpneumophila pneumonia than healthy individuals [73-75].
In both treated and untreated HIV, Legionella nonpneumophila infections commonly manifest as fever, cough, dyspnea, diarrhea, pleuritic chest pain, and effusion, with documented instances of pulmonary cavities, nodules, and lung abscesses [73, 75-77]. Studies from the pre-cART era indicate that higher mortality rates are associated with infection in untreated HIV, although this may be due to the fact that these infections have only been reported in severely immunosuppressed patients and may not be due to the virulence of the microbes themselves [77-79].

Diagnosis of HIV-associated non-pneumophila Legionella pneumonia requires high clinical suspicion. Until a definitive diagnosis is reached, aggressive empirical therapy should be administered, especially in immunodeficient patients, in order to ensure a more positive outcome. Indeed, discontinuing empiric therapy in an immunocompromised adult HIV-infected individual despite a high suspicion of Legionella infection can lead to fatality [77].

Currently, culture is the best at diagnosing nonpneumophila pneumonia in HIV; however, sensitivities vary depending on the laboratory, with higher sensitivities having only been recorded in laboratories with a special interest in legionellosis [73, 75-77, 80, 81]. Urinary antigen, although useful for L. pneumophila serogroup 1 detection, is less sensitive for other serogroups and is practically useless for non-pneumophila species $[77,82]$. NAAT methods, specifically PCR of lower respiratory tract specimens, have demonstrated high sensitivities (up to 100\%) with Legionella species and may be a possible alternative for detecting nonpneumophila Legionella pneumonia in HIV-infected patients. However, although PCR assays can detect all of the various Legionella species with high specificity, they are currently not readily available for clinical use [17].

Little is known about non-pneumophila pneumonia and its prevalence in HIV, which may simply be due to the fact that L. pneumophila serogroup 1 is typically the only Legionella species that is often considered; the urinary antigen test targets L. pneumophila serogroup 1 and so do many serological assays [76]. The distribution of Legionella varies globally, therefore the usefulness of the urinary antigen test should be validated in each locale [83]. Moreover, HIV-associated legionellosis due to non-pneumophila is similar to L. pneumophila, which could prevent differentiation between these infections. To better determine the role of these pathogens in HIV infection, further development of more appropriate diagnostic techniques and increased clinical awareness are required.

\section{Tropheryma whipplei}

Tropheryma whipplei, although not usually considered one of the atypical bacteria, has been found in respiratory samples of treated HIV-infected individuals at higher prevalence rates than the general population [84-87]. Currently, 
it is unclear whether $T$. whipplei is a pneumonia-causing pathogen or merely a commensal organism, since it has been found in both symptomatic and asymptomatic cases alike [84, 88-90]. Although some studies report T. whipplei as a pathogen (and even attribute certain clinical manifestations to this bacterium), caution is required until more evidence is acquired about the role of this microbe in HIVassociated pneumonia.

\section{Treatment of atypical bacterial pneumonia in HIV}

Unlike typical bacterial pneumonia, atypical bacterial pneumonia does not respond to beta-lactams, aminoglycosides, and sulfa drugs; therefore, a 7-10 day course of macrolides (clarithromycin, erythromycin, or azithromycin), doxycycline and/or fluoroquinolones (levofloxacin or moxifloxacin) are required to treat these infections in HIV patients [29, 57, 62, 66, 91].

\section{Conclusions}

Bacterial pneumonia is an immense problem among immunocompromised HIV-infected individuals, contributing to the high morbidity and eventual death of these patients. Although a large proportion of pneumonia is attributable to typical bacterial infections, clinicians must be aware of other relevant pathogens, such as $C$. pneumoniae, M. pneumoniae, C. burnetti, Legionella species, and, possibly, T. whipplei.

Diagnosing HIV-associated atypical pneumonia remains a challenging task and becomes even more so when the patient is severely immunocompromised. Due to the lack of data, the lack of consideration, and the current subpar diagnostic methods, atypical bacterial pneumonia is often left undiagnosed in HIV-infected individuals. Studies using more invasive methods (e.g. bronchoscopy and BAL) may provide a more accurate depiction of pneumonia. Further studies, and the development of more appropriate diagnostic methods, are required to clarify the role and prevalence rates of atypical bacterial pneumonia in HIV.

\section{Abbreviations \\ AIDS: Acquired immunodeficiency syndrome; BAL: Bronchoalveolar lavage; CART: Combination antiretroviral therapy; HIV: Human immunodeficiency virus; IFA: Immunofluorescence assay; MIF: Microimmunofluorescence; NAAT: Nucleic acid amplification techniques; PCR: Polymerase chain reaction}

\section{Acknowledgements}

Not applicable.

\section{Funding}

This project is supported by funding from Colciencias (grant number: 111571249880). The funder had no role in the preparation of the manuscript nor the decision to publish.

\section{Availability of data and materials}

Data sharing not applicable to this article as no datasets were generated or analysed during the current study and all information obtained during this literature search is publically available through PubMed.

\section{Authors' contributions}

$\mathrm{BH}$ conducted the literature search as well as drafted the review manuscript. $\mathrm{BH}$ also consulted with AT, ZR, LV and YK, for guidance, editing and to critically revise the intellectual content of the manuscript. All authors read and approved the final manuscript.

Ethics approval and consent to participate

Not applicable.

Consent for publication

Not applicable.

\section{Competing interests}

The authors declare that they have competing interests.

\section{Publisher's Note}

Springer Nature remains neutral with regard to jurisdictional claims in published maps and institutional affiliations.

\section{Author details}

${ }^{1}$ Department of Medical Microbiology, University of Manitoba, Winnipeg, Canada. ${ }^{2}$ Facultad de Medicina, Universidad Pontificia Bolivariana, Medellin, Colombia. ${ }^{3}$ Grupo Investigador de Problemas en Enfermedades Infecciosas, Universidad de Antioquia UdeA, Medellin, Colombia. ${ }^{4}$ Department of Internal Medicine, University of Manitoba, Winnipeg, Canada. ${ }^{5}$ Department of Community Health Sciences, University of Manitoba, Winnipeg, Canada.

Received: 10 April 2017 Accepted: 13 July 2017

Published online: 25 August 2017

\section{References}

1. Kaplan JE, Benson C, Holmes KK, Brooks JT, Pau A, Masur H. Guidelines for prevention and treatment of opportunistic infections in HIV-infected adults and adolescents. MMWR. 2009;58:1-198.

2. Segal LN, Methé BA, Nolan A, Hoshino Y, Rom WN, Dawson R, et al. HIV-1 and bacterial pneumonia in the era of antiretroviral therapy. Proc Am Thorac Soc. 2011;8:282-7. doi:10.1513/pats.201006-044WR.

3. Cordero E, Pachón J, Rivero A, Girón JA, Gómez-mateos J, Collado A, et al. Community-acquired bacterial pneumonia in human immunodeficiency virus - infected patients. Am J Respir Crit Care Med. 2000;162:2063-8.

4. Pedro-Botet ML, Sopena N, García-Cruz A, Mateu L, García-Núñez M, ReyJoly C, et al. Streptococcus pneumoniae and Legionella pneumophila pneumonia in HIV-infected patients. Scand J Infect Dis. 2007;39:122-8. doi:10.1080/00365540600951275

5. Benito N, Moreno A, Miro JM, Torres A. Pulmonary infections in HIV-infected patients: an update in the 21st century. Eur Respir J. 2012;39:730-45. doi:10.1183/09031936.00200210.

6. Mangtania P, Mulhollanda K, Madhib SA, Edmonda K, O'Loughlina R, Hajjehc R. Haemophilus influenzae type $b$ disease in HIV-infected children: a review of the disease epidemiology and effectiveness of Hib conjugate vaccines. Vaccine. 2010;28:1677-83.

7. Hidron Al, Kempker R, Moanna A, Rimland D. Methicillin-resistant Staphylococcus aureus in HIV-infected patients. Infect Drug Resist. 2010;3:73-86.

8. Auwaerter P. Johns Hopkins HIV Guide. Johns Hopkins Med 2016. https:// www.hopkinsguides.com/hopkins/view/Johns_Hopkins_HIV_Guide/545087/ all/Haemophilus_species. Accessed 5 June 2017.

9. Benito N, Rañó A, Moreno A, González J, Luna M, Agustí C, et al. Pulmonary infiltrates in HIV-infected patients in the HAART era in Spain. J Acquir Immune Defic Syndr. 2001;27:35-43.

10. Morris AM, Huang L, Bacchetti P, Turner J, Hopewell PC, Wallace JM, et al. Permanent declines in pulmonary function following pneumonia in human immunodeficiency virus-infected persons. Am J Respir Crit Care Med. 2000;162:612-6.

11. Thompson LH, Sochocki M, Friesen T, Bresler K, Keynan Y, Kasper K, et al. Medical ward admissions among HIV-positive patients in Winnipeg, Canada, 2003-10. Int J STD AIDS. 2012;23:287-8. doi:10.1258/ijsa.2011.011309.

12. Van Gaalen S, Rueda Z, Arroyave L, Kasper K, Keynan Y. Characteristics of pneumonia admissions in HIV-positive individuals: a single-centre, 10 -year cross-sectional retrospective analysis. J Assoc Med Microbiol Infect Dis Canada. 2016;1:SP08. 
13. Lazarous DG, O'Donnell AE. Pulmonary infections in the HIV-infected patient in the era of highly active antiretroviral therapy: an update. Curr Infect Dis Rep. 2007;9:228-32.

14. Chalmers J. The modern diagnostic approach to community-acquired pneumonia in adults. Semin Respir Crit Care Med. 2016;37:876-85. doi:10. 1055/s-0036-1592125.

15. Basnayake TL, Waterer GW. Rapid diagnostic tests for defining the cause of community-acquired pneumonia. Curr Opin Infect Dis. 2015;28:185-92. doi:10.1097/QCO.0000000000000148.

16. McMichael AJ, Borrow P, Tomaras GD, Goonetilleke N, Haynes BF. The immune response during acute HIV-1 infection: clues for vaccine development. Nat Rev Immunol. 2010;10:11-23. doi:10.1038/nri2674.The

17. Phin N, Parry-Ford F, Harrison T, Stagg HR, Zhang N, Kumar K, et al. Epidemiology and clinical management of legionnaires' disease. Lancet Infect Dis. 2014;14:1011-21. doi:10.1016/S1473-3099(14)70713-3.

18. Prina E, Ranzani OT, Torres A. Community-acquired pneumonia. Lancet. 2015:386:1097-108. doi:10.1016/ S0140-6736(15)60733-4.

19. Herrera M, Aguilar YA, Rueda ZV, Muskus C, Vélez LA. Comparison of serological methods with PCR-based methods for the diagnosis of community-acquired pneumonia caused by atypical bacteria. J Negat Results Biomed. 2016;15:1-11. doi:10.1186/s12952-016-0047-y.

20. Weiss D, Boyd C, Rakeman JL, Greene SK, Fitzhenry R, McProud T, et al. A large community outbreak of legionnaires' disease associated with a cooling tower in new York City, 2015. Public Health Rep. 2017;132:241-50. doi:10.1177/0033354916689620.

21. UCLA Healthcare. Bronchoscopy with or without biopsy. UCLA Healthcare. 2003. https://www.uclahealth.org/lungcancer/workfiles/Bronchoscopy_ consent.pdf. Accessed 5 June 2017.

22. Mandell LA, Wunderink RG, Anzueto A, Bartlett JG, Campbell GD, Dean NC, et al. Infectious diseases society of America/American Thoracic Society consensus guidelines on the management of community-acquired pneumonia in adults. Clin Infect Dis. 2007:44:S27-72. doi:10.1086/511159.

23. Montes M, Cilla G, Alcorta M, Pérez-Trallero E. High prevalence of Chlamydia pneumoniae infection in children and young adults in Spain. Pediatr Infect Dis J. 1992;11:972-3.

24. Koh WP, Taylor MB, Hughes K, Chew SK, Fong CW, Phoon MC, et al. Seroprevalence of IgG antibodies against Chlamydia pneumoniae in Chinese, Malays and Asian indians in Singapore. Int J Epidemiol. 2002;31:1001-7. doi:10.1093/ije/31.5.1001

25. Comandini UV, Massetti AP, Marchese R, Zaccarelli M, Vullo V, Delia S. Chlamydia pneumoniae seroprevalence among HIV-1-infected and uninfected people with known HIV risk factor. AIDS. 1996;10:1543-7.

26. Trinh QD, Pham NT, Le Nguyen NT, Lam BQ, Le Phan KT, Truong KH, et al. Frequent Chlamydophila pneumoniae infection in vertically HIV-infected children in Vietnam. J Reprod Immunol. 2014;106:17. doi:10.1016/j.jri.2014.09.042.

27. Trinh QD, Pham NTK, Le Nguyen NT, Lam BQ, Le Phan KT, Truong KH, et al. Seroprevalence of Chlamydophila pneumoniae in HIV-infected children in Vietnam. J Infect Chemother. 2013;19:538-41. doi:10.1007/s10156-012-0483-7.

28. Tositti G, Rassu M, Fabris P, Giordani M, Cazzavillan S, Reatto P, et al. Chlamydia pneumoniae infection in HIV-positive patients: prevalence and relationship with lipid profile. HIV Med. 2005:6:27-32.

29. Comandini UV, Maggi P, Santopadre P, Monno R, Angarano G, Vullo V. Chlamydia pneumoniae respiratory infections among patients infected with the human immunodeficiency virus. Eur J Clin Microbiol Infect Dis. 1997;16:720-6.

30. Boschini A, Smacchia C, Fine M Di, Schiesari A, Ballarini P, Arlotti M, et al. Community-acquired pneumonia in a cohort of former injection drug users with and without human immunodeficiency virus infection : incidence, etiologies, and clinical aspects. Clin Infect Dis 1996;23:107-113.

31. Figueiredo-Mello C, Naucler P, Negra MD, Levin AS. Prospective etiological investigation of community-acquired pulmonary infections in hospitalized people living with HIV. Medicine (Baltimore). 2017;96:e5778. doi:10.1097/MD. 0000000000005778

32. Hammerschlag MR, Chirgwin K, Roblin PM, Gelling M, Dumornay W, Mandel $L$, et al. Persistent infection with Chlamydia pneumoniae following acute respiratory illness. Clin Infect Dis. 1992;14:178-82.

33. Blasi F, Cosentini R, Schoeller MC, Lupo A, Allegra L. Chlamydia pneumoniae seroprevalence in immunocompetent and immunocompromised populations in Milan. Thorax. 1993:48:1261-3. doi:10.1136/thx.48.12.1261.

34. Kuo CC, Jackson L, Cambell L, Grayston T. Chlamydia pneumoniae. Clin Microbiolgy Rev. 1995;8:451-61.

35. Miller R. HIV-associated respiratory diseases. Lancet. 1996;348:307-12.
36. Woolley IJ, Larsen M, Jones S, Gahan ME, Jasenko I, Johnsen SP, et al. Chlamydia pneumoniae in HIV-infected patients and controls assessed by a novel whole blood interferon- $\gamma$ assay, serology and PCR. Clin Microbiol Infect. 2004;10:820-5.

37. Baron EJ, Miller JM, Weinstein MP, Richter SS, Gilligan PH, Thomson RB, et al. A guide to utilization of the microbiology laboratory for diagnosis of infectious diseases: 2013 recommendations by the Infectious Diseases Society of America (IDSA) and the American Society for Microbiology (ASM). Clin Infect Dis. 2013;57:485-8. doi:10.1093/cid/cit441.

38. Shankar EM, Kumarasamy N, Balakrishnan P, Vengatesan A, Kownhar H, Solomon S, et al. Seroprevalence of Mycoplasma pneumoniae in HIVinfected patients using a microparticle agglutination test. J Med Microbiol. 2006:55:759-63. doi:10.1099/jmm.0.46402-0.

39. Rao U, Shankar E, Kumarasamy N, Balakrishnan P, Solomon S. Pulmonary microbiology of HIV positive subjects with community-acquired pneumonia (CAP) with special emphasis on Mycoplasma pneumoniae. Int J Infect Dis. 2010;14:e401. doi:10.1016/j.jijid.2010.02.511.

40. Stevens CD, Miller LE. Serological and molecular detection of bacterial infections. In: DeChambeau DW, Bales E, editors. Clin. Immunol. Serol. A lab. Perspect. 4th ed., Philadelphia: F.A. Davis Company; 2017, p. 346-362.

41. Nadagir SD, Bahadur AK, Shepur TA. Prevalence of Mycoplasma pneumoniae among HIV infected children. Indian J Pediatr. 2011;78:430-4. doi:10.1007/ s12098-010-0313-9.

42. Shankar EM, Kumarasamy N, Balakrishnan P, Saravanan S, Solomon S, Vengatesan A, et al. Detection of pulmonary Mycoplasma pneumoniae infections in HIV-infected subjects using culture and serology. Int J Infect Dis. 2007;11:232-8. doi:10.1016/j.ijid.2006.04.007.

43. Shankar EM, Kumarasamy N, Balakrishnan P, Solomon S, Devaleenol B, Rao UA. Incidence of Mycoplasma pneumoniae infection in HIV-infected patients with underlying upper and lower respiratory complaints and correlation with various immunological and haematological findings. Retrovirology. 2005;2:S97. doi:10.1186/1742-4690-2-S1-S97.

44. Ling CL, McHugh TD. Rapid Detection of Atypical Respiratory Bacterial Pathogens by Real-Time PCR. In: Wilks M, editor. PCR Detect. Microb. Pathog. 2nd ed., Springer Science; 2013, p. 125-33. doi:10.1007/978-1-62703-239-1_1.

45. Shankar EM, Kumarasamy N, Balakrishnan P, Solomon S, Lejith R, Vengatesan A, et al. Serosurveillance of acute Mycoplasma pneumoniae infection among HIV infected patients with pulmonary complaints in Chennai, southern India. J Inf Secur. 2006;53:325-30. doi:10.1016/j.jinf.2005.11.184.

46. Hammerschlag MR. Mycoplasma pneumoniae infections. Curr Opin Infect Dis. 2001;14:181-6. doi:10.1016/B978-032303506-4.10222-6.

47. Sillis M. The limitations of lgM assays in the serological diagnosis of Mycoplasma pneumoniae infections. J Med Microbiol. 1990;33:253-8.

48. Petitjean J, Vabret A, Gouarin S, Freymuth F. Evaluation of four commercial immunoglobulin G (lgG)- and lgM-specific enzyme immunoassays for diagnosis of Mycoplasma pneumoniae infections. J Clin Microbiol. 2002;40: 165-71. doi:10.1128/JCM.40.1.165.

49. Atkinson T, Duffy LB, Pendley D, Dai Y, Cassell GH. Reduced IgG antibody to Mycoplasma pneumoniae among subjects with asthma: results of a five year study. J Allergy Clin Microbiol. 2005;115:S171.

50. Waites KB, Talkington DF. Mycoplasma pneumoniae and its role as a human pathogen. Clin Microbiol Rev. 2004;17:697-728. doi:10.1128/CMR.17.4.697.

51. Twigg HL III, Spain BA, Soliman DM, Bowen LK, Heidler KM, Wilkes DS. Impaired IgG production in the lungs of HIV-infected individuals. Cell Immunol. 1996;170:127-33.

52. Bartlett JG. Diagnostic tests for agents of community-acquired pneumonia. Clin Infect Dis. 2011;52 doi:10.1093/cid/cir045.

53. Boschini A, Perri GD, Legnani D, Fabbri P, Ballarini P, Zucconi R, et al. Consecutive epidemics of $Q$ fever in a residential facility for drug abusers: impact on persons with human immunodeficiency virus infection. Clin Infect Dis. 1999;28:866-72.

54. Raoult D, Levy P-Y, Tissot Dupont H, Chicheportiche C, Tamalet C, Gastaut J-A, et al. Q fever in HIV infection. AIDS. 1993:81-6.

55. Jaton K, Peter O, Raoult D, Tissot JD, Greub G. Development of a high throughput PCR to detect Coxiella burnetii and its application in a diagnostic laboratory over a 7-year period. New Microbes New Infect. 2013; 1:6-12. doi:10.1002/2052-2975.8.

56. Lamas CC, Rozental T, Bóia MN, Favacho AR, Kirsten AH, Da Silva AP, et al. Seroprevalence of Coxiella burnetii antibodies in human immunodeficiency virus-positive patients in Jacarepaguá, Rio de Janeiro, Brazil. Clin Microbiol Infect. 2009;15(2):140-1. doi:10.1111/j.1469-0691.2008.02144.X. 
57. Madariaga MG, Pulvirenti J, Sekosan M, Paddock CD, Zaki SR. Q fever endocarditis in HIV-infected patient. Emerg Infect Dis. 2004;10:501-4.

58. Pedro-Botet ML, Sabrià M, Sopena N, García-Núñez M, Jesús Dominguez M, Reynaga E, et al. Legionnaires disease and HIV infection. Chest. 2003;124: 543-7. doi:10.1378/chest.124.2.543.

59. Bangsborg JM, Jensen BN, Friis-Moller A, Bruun B. Legionellosis in patients with HIV infection. Infection. 1990;18:342-6. doi:10.1007/BF01646400.

60. Blatt SP, Dolan MJ, Hendrix CW, Melcher GP. Legionnaires' disease in human immunodeficiency virus-infected patients: eight cases and review. Clin Infect Dis. 1994;18:227-32.

61. Rodero FG, Ortiz de la Tabla V, Martínez C, del AMr Masiá M, Chiner E, Calpe $J$ L. Legionnaires' disease in patients infected with human immunodeficiency virus. Clin Infect Dis. 1995:21:712-3.

62. Franzin L, Dal Conte I, Cabodi D, Sinicco A. Culture proven Legionella pneumophila pneumonia in a HIV-infected patient: case report and review. J Inf Secur. 2002;45:199-201. doi:10.1016/S0163-4453(02)91030-3.

63. Marston BJ, Lipman HB, Breiman RF. Surveillance for legionnaires' disease: risk factors for morbidity and mortality. Arch Intern Med. 1994;154:2417-22. doi:10.1001/archinte.1994.00420210049006.

64. Wolter N, Carrim M, Cohen C, Tempia S, Walaza S, Sahr P, et al. Legionnaires' disease in South Africa, 2012-2014. Emerg Infect Dis. 2016;22: 131-3. doi:10.3201/eid2201.150972.

65. Pedro-botet ML, Sabria-Leal M, Sopena N, Manterola JM, Morera J, Blavia R, et al. Role of immunosuppression in the evolution of legionnaires' disease. Clin Infect Dis. 1998:26:14-9.

66. Sandkovsky U, Sandkovsky G, Suh J, Smith B, Sharp V, Polsky B. Legionella pneumonia and HIV: case reports and review of the literature. AIDS Patient Care STDs. 2008:22:473-81. doi:10.1089/apc.2007.0111.

67. Robbins NM, Kumar A, Blair BM. Legionella pneumophila infection presenting as headache, confusion and dysarthria in a human immunodeficiency virus1 (HIV-1) positive patient: case report. BMC Infect Dis. 2012;12:1-6. doi:10. 1186/1471-2334-12-225.

68. Edelstein PH, Edelstein MAC. In vitro activity of the ketolide HMR 3647 (RU 6647) for Legionella spp., its pharmacokinetics in guinea pigs, and use of the drug to treat guinea pigs with Legionella pneumophila pneumonia. Antimicrob Agents Chemother. 1999;43:90-5.

69. Edlestein PH. Legionnaires' disease. Clin Infect Dis. 1993;16:741-9.

70. Rathore MH. Legionella infection workup. Medscape 2016:1-2. http:// emedicine.medscape.com/article/965492-workup. Accessed 4 June 2017.

71. Benitez AJ, Winchell JM. Clinical application of a multiplex real-time PCR assay for simultaneous detection of Legionella species, Legionella pneumophila, and Legionella pneumophila serogroup 1. J Clin Microbiol. 2013;51:348-51. doi:10.1128/JCM.02510-12.

72. Cross KE, Mercante JW, Benitez AJ, Brown EW, Diaz MH, Winchell JM. Simultaneous detection of Legionella species and L. anisa, L. bozemanii, L. longbeachae and L. micdadei using conserved primers and multiple probes in a multiplex real-time PCR assay. Diagn Microbiol Infect Dis. 2016;85: 295-301. doi:10.1016/j.diagmicrobio.2016.03.022.

73. Nzerue C, Gowda A. Legionella micdadei lung abscess in a patient with HIVassociated nephropathy. J Natl Med Assoc. 2001;93:220-3.

74. Taylor TH, Albrecht MA. Legionella bozemanii cavitary pneumonia poorly responsive to erythromycin: case report and review. Clin Infect Dis. 1995;20: 329-34. doi:10.1093/clinids/20.2.329.

75. Harris A, Lally M, Albrecht M. Legionella bozemanii pneumonia in three patients with AIDS. Clin Infect Dis. 1998;27:97-9.

76. Twigg HL III, Weinstock GM, Knox KS. Lung microbiome in HIV infection. Transl Res. 2016:1-11. doi:10.1016/j.trsl.2016.07.008.

77. Dumoff K, McGovern PC, Edelstein PH, Nachamkin I. Legionella maceachernii pneumonia in a patient with HIV infection. Diagn Microbiol Infect Dis. 2004; 50:141-5. doi:10.1016/j.diagmicrobio.2004.06.011.

78. Fang GD, Yu VL, Vickers RM. Disease due to the Legionellaceae (other than Legionella pneumophila). Historical, microbiological, clinical, and epidemiological review. Medicine (Baltimore). 1989;68:116-32. http://dx.doi.org/10.1097/00005792-198903000-00005.

79. Willkinson HW, Lanier Thacker W, Brenner DJ, Ryan KJ. Fatal Legionella maceachernii pneumonia. J Clin Microbiol. 1985;22:1055.

80. Sopena N, Sabrià-Leal M, Pedro-Botet ML, Padilla E, Dominguez J, Morera J, et al. Comparative study of the clinical presentation of Legionella pneumonia and other community-acquired pneumonias. Chest. 1998;113:1195-200. doi:10.1378/chest.113.5.1195.
81. Zuravleff JJ, Yu VL, Shonnard JW, Zuravleff JJ, Yu VL, Shonnard JW, et al. Diagnosis of legionnaires' disease. An update of laboratory methods with new emphasis on isolation by culture. JAMA J Am Med Assoc. 1983;250: 1981-5. doi:10.1001/jama.250.15.1981.

82. Yu VL, Plouffe JF, Pastoris MC, Stout JE, Schousboe M, Widmer A, et al. Distribution of Legionella species and serogroups isolated by culture in patients with sporadic community-acquired legionellosis: an international collaborative survey. J Infect Dis. 2002;186:127-8. doi:10.1097/00019048200205000-00039.

83. Plouffe JF, Breiman RF, Fields BS, Herbert M, Inverso J, Knirsch C, et al. Azithromycin in the treatment of Legionella pneumonia requiring hospitalization. Clin Infect Dis. 2003;37:1475-80. doi:10.1086/379329.

84. Fenollar F, Ponge T, La Scola B, Lagier JC, Lefebvre M, Raoult D. First isolation of Tropheryma whipplei from bronchoalveolar fluid and clinical implications. J Inf Secur. 2012;65:275-8. doi:10.1016/j.jinf.2011.11.026.

85. Desnues B, Al Moussawi K, Fenollar F. New insights into Whipple's disease and Tropheryma whipplei infections. Microbes Infect. 2010;12:1102-10. doi:10.1016/j.micinf.2010.08.001.

86. Raoult D, Fenollar F, Birg M-L. Culture of T. Whipplei from the stool of a patient with Whipple's disease. N Engl J Med. 2006:355:1503-5. doi:10.1056/ NEJMC061049.

87. Edouard S, Fenollar F, Raoult D. The rise of Tropheryma whipplei: a 12-year retrospective study of PCR diagnoses in our reference center. J Clin Microbiol. 2012;50:3917-20. doi:10.1128/JCM.01517-12.

88. Marth T, Moos V, Müller C, Biagi F, Schneider T. Tropheryma whipplei infection and whipple's disease. Lancet. 2016;16:e13-22. doi:10.1016/S14733099(15)00537-X.

89. Fenollar F, Laouira S, Lepidi H, Rolain J, Raoult D. Value of Tropheryma whipplei quantitative polymerase chain reaction assay for the diagnosis of Whipple disease: usefulness of saliva and stool specimens for first-line screening. Clin Infect Dis. 2008:47:659-67. doi:10.1086/590559.

90. Lozupone C, Cota-Gomez A, Palmer BE, Linderman DJ, Charlson ES, Sodergren $\mathrm{E}$, et al. Widespread colonization of the lung by Tropheryma whipplei in HIV infection. Am J Respir Crit Care Med. 2013;187:110-1117. doi:10.1164/rccm.201211-21450C.

91. Pereyre S, Goret J, Bébéar C. Mycoplasma pneumoniae: current knowledge on macrolide resistance and treatment. Front Microbiol. 2016;7:1-11. doi:10.3389/fmicb.2016.00974.

\section{Submit your next manuscript to BioMed Central and we will help you at every step:}

- We accept pre-submission inquiries

- Our selector tool helps you to find the most relevant journal

- We provide round the clock customer support

- Convenient online submission

- Thorough peer review

- Inclusion in PubMed and all major indexing services

- Maximum visibility for your research

Submit your manuscript at www.biomedcentral.com/submit 